К. М. Югов, М. Ю. Зайков. Смерть от акцидентальной гипотермии и экспертная оценка степени алкогольной интоксикации

Научная статья

УДК 613.81

DOI: $10.18101 / 2306-1995-2021-2-23-28$

\title{
СМЕРТЬ ОТ АКЦИДЕНТАЛЬНОЙ ГИПОТЕРМИИ И ЭКСПЕРТНАЯ ОЦЕНКА СТЕПЕНИ АЛКОГОЛЬНОЙ ИНТОКСИКАЦИИ
}

\section{(C) Югов Константин Михайлович}

кандидат медицинских наук, старший преподаватель, Бурятский государственный университет имени Доржи Банзарова Россия, 670031, г. Улан-Удэ, ул. Октябрьская, 36а buryatia@sudmed.info

\author{
(c) Зайков Максим Юрьевич \\ старший преподаватель, \\ Бурятский государственный университет имени Доржи Банзарова \\ Россия, 670024, г. Улан-Удэ, ул. Октябрьская, 36а \\ maksim_skuchayu@mail.ru
}

\begin{abstract}
Аннотация. Смертность от острой акцидентальной гипотермии в структуре насильственной смерти в различных регионах России составляет от 1,14 до 7,4\%. Наиболее часто гибель людей отмечалась в возрастной группе 41-50 лет, то есть наиболее работоспособной части населения, а мужчины составляли около $75 \%$ погибших.

Основная цель работы заключалась в том, чтобы разработать и обосновать судебномедицинские критерии оценки степени алкогольной интоксикации при смерти от общего переохлаждения организма на основе изучения концентрации этанола в различных биологических средах с учетом особенностей его метаболизма при данном виде смерти.

Разработана и успешно апробирована на практическом судебно-медицинском материале методика объективной оценки степени алкогольной интоксикации у погибших от переохлаждения, включающая в себя следующие позиции: установление типа об его переохлаждения; определение стадии алкогольной интоксикации в момент наступления смерти; обязательное токсикологическое исследование на этанол желчи и стекловидного тела, которые являются стабильными системами при переохлаждении организма; использование для расчета «истинной» алкоголизации организма разработанной математической формулы и рассчитанных нами поправочных коэффициентов.
\end{abstract}

Ключевые слова: акцидентальная гипотермия, алкогольная интоксикация, смертность, насильственная смертность, судебно-медицинские критерии.

\section{Для цитирования}

Югов К. М., Зайков М. Ю. Смерть от акцидентальной гипотермии и экспертная оценка степени алкогольной интоксикации // Вестник Бурятского государственного университета. Медицина и фармация. 2021. № 2. С. 23-28.

Общеизвестно, что смерть от общего переохлаждения организма встречается практически во всех географических широтах. На территории Российской Федерации, большая часть которой расположена в зонах холодного или умеренного климата, смерть от холода является одной из актуальных проблем медицины [1]. Смертность от острой акцидентальной гипотермии в структуре насильственной 
смерти в различных регионах страны составляет от 1,14 до 7,4\% [3; 5]. Особое значение данная проблема имеет в Сибири, которую Михаил Иванович Райский называл «классической страной холода» $2 ; 8]$. Только в одном из типичных Сибирских регионов - Байкальском, включающем Иркутскую область и Республику Бурятия, от действия низкой температуры окружающей среды в среднем ежегодно погибает около 250-300 человек [3; 11]. За последние 10 лет смерть от переохлаждения среди всей насильственной смерти регистрировалась здесь в $2,8 \%$ случаев, колеблясь в разные годы от 1,2 до 3,5\% [2]. Наиболее часто гибель людей отмечалась здесь в возрастной группе $41-50$ лет, то есть наиболее работоспособной части населения, а мужчины составляли около $75 \%$ погибших [5; 6].

Известно, что одним из основных факторов риска, способствующих наступлению смерти от переохлаждения, является употребление спиртных напитков. Частота встречаемости этанола в крови погибших от действия низкой температуры достаточно высока и, по данным большинства авторов, колеблется от 59,4 до $76,0 \%[4 ; 10]$. В Иркутской области и Республике Бурятия данный показатель составляет 75,5\% [1].

Многими исследователями было доказано, что алкогольная интоксикация существенно влияет на способность человека совершать активные целенаправленные действия, осуществляемые с целью самоспасения в возникшей экстремальной ситуации. Прием спиртных напитков приводит к значительному повышению теплоотдачи, снижает адаптационные возможности организма, вызывает состояние малой физической активности человека, что выражается слабостью, сонливостью, стремлением пострадавших прилечь ${ }^{1}$.

В связи с этим чрезвычайно важной является оценка степени алкогольной интоксикации у лиц, погибших от переохлаждения организма. Однако решение данного вопроса намечено лишь на основе результатов количественного определения концентрации этанола в крови. Полученный уровень экзогенной алкоголемии сопоставляется со степенью алкогольного опьянения на основании официальных ведомственных методических указаний «О судебно-медицинской диагностике смертельных отравлений этиловым алкоголем и допускаемых при этом ошибках», утвержденных Главной судебно-медицинской экспертизой Минздрава Союза ССР ещё в 1974 г. Приведенная в этом документе классификация предназначена для определения степени опьянения у живых лиц и не учитывает характер и степень воздействия физических факторов на человека, в том числе холодовых, в период, предшествующий наступлению смерти ${ }^{2}$ [9].

Вместе с тем в работах В. П. Десятова, Р. В. Бережного, В. В. Томилина, Ф. А. Галицкого и других ученых, проведенных в конце 20-го столетия, достоверно установлено, что в процессе умирания от переохлаждения происходит существенное снижение концентрации алкоголя в организме в связи с утилизацией этанола как энергетического материала, что отражается в первую очередь на содержании его в крови. Кроме того, рядом авторов (А. В. Орлов, Н. В. Рухляда, Ю. Г. Доронин, В. А. Новиков, В. Д. Исаков, А. Ю. Чудаков) было показано, что

\footnotetext{
${ }^{1}$ О судебно-медицинской диагностике смертельных отравлений этиловым алкоголем и допускаемых при этом ошибках: метод. указания Минздрава СССР от 03.07.74. Москва, 1974. $17 \mathrm{c}$.

2 Там же.
} 
К. М. Югов, М. Ю. Зайков. Смерть от акцидентальной гипотермии и экспертная оценка степени алкогольной интоксикации

при смертельной гипотермии имеют место глубокие морфо-функциональные нарушения, в том числе и гемодинамические изменения, связанные с централизацией кровообращения, дегидратацией периферических тканей, отеком внутренних органов, повышением вязкости крови, снижением скорости ее циркуляции и объема, что оказывает значительное влияние на протекание физико-химических процессов поступления, распределения, каталитического окисления и выделения экзогенного алкоголя $[7 ; 11]$.

Поэтому, несмотря на свою значимость, концентрационный уровень алкоголемии не может отражать истинного содержания этанола в организме и служить критерием степени снижения психофизиологической дееспособности пострадавших.

В связи с этим основная цель работы состояла в том, чтобы разработать и обосновать судебно-медицинские критерии оценки степени алкогольной интоксикации при смерти от общего переохлаждения организма на основе изучения концентрации этанола в различных биологических средах с учетом особенностей его метаболизма при данном виде смерти.

Для достижения поставленной цели был изучен секционный материал, объектами которого явились 120 трупов лиц обоего пола, из них в 80 случаях причиной смерти явилась общая воздушная акцидентальная гипотермия в состоянии алкогольной интоксикации, и в 40 случаях регистрировали смерть от различных причин при отсутствии влияния на организм низкой температуры окружающей среды перед наступлением смерти. Последние наблюдения составили контрольную группу, в которую вошли 19 лиц, умерших от ишемической болезни сердца, $15-$ механической асфиксии и 6 - механической травмы, несовместимой с жизнью. В контрольную группу включали только трупы лиц, у которых на момент смерти определяли алкогольную интоксикацию в стадии равновесия (20) либо в стадии элиминации (20). Это было связано с тем, что при смертельной гипотермии мы никогда не наблюдали стадию резорбции. Давность смерти на момент вскрытия во всех наблюдениях не превышала 72 часов.

Кроме полного судебно-медицинского обследования трупов по Шору проводили гистологическое исследование микропрепаратов, изготовленных путем заливки кусочков тканей и внутренних органов в парафин или целлоидин с последующей окраской срезов гематоксилин-эозином. В день проведения вскрытия трупа определяли количественное содержание этанола в 11 жидких средах организма, включая кровь из 7 отделов сосудистого русла, в том числе синусов твердой мозговой оболочки, левых и правых отделов сердца, из воротной и бедренной вен, с плоскостей разрезов легких и печени, а также ликвор, мочу, желчь и стекловидное тело. Химический анализ осуществляли газохроматографическим методом с использованием хроматографа модели МХК. В тех же средах устанавливали содержание глюкозы ортотолуидиновым методом. Кроме того, проводили гистохимические исследования на гликоген препаратов печени, скелетной и сердечной мышцы по методике Беста. В этих же объектах устанавливали содержание гликогена и глюкозы калориметрическим микрометодом по Кемпу и Китрес.

На основании полученных результатов количественного содержания этанола в жидких средах организма были сформированы базы данных, которые подвергали 
математической обработке с вычислением статистических показателей, используя компьютерную программу Биостат.

Для определения типа переохлаждения использовали разработанную нами дифференциально-диагностическую схему, позволяющую достоверно устанавливать «быстрый» или «медленный» типы переохлаждения. Причем одним из важных используемых диагностических признаков являлся уровень гликогена в печени, скелетной и сердечной мышцах. Различия рассчитанных нами средних значений содержания гликогена в этих тканях во всех исследуемых группах были статистически значимыми $(\mathrm{p}<0,05)$.

Таким образом, группу погибших от «быстрого» типа переохлаждения составили 26 наблюдений, группу погибших от «медленного» типа переохлаждения 54 наблюдения.

Было выявлено, что при смерти от «быстрого» типа переохлаждения чаще наблюдается уровень алкоголемии, соответствующий средней и сильной степени алкогольной интоксикации $(73,0 \%)$, и констатируется либо стадия равновесия, либо элиминации. При смерти от «медленного» типа переохлаждения чаще диагностировали легкую степень алкогольной интоксикации $(59,3 \%)$ и только стадию элиминации.

При сравнительном исследовании содержания этанола в крови, полученной из разных отделов сосудистого русла, во всех исследуемых группах выявлены существенные различия в пределах объектов одного наблюдения. Однако разница в концентрациях максимального и минимального уровней этанола в крови погибших от «медленного» типа переохлаждения значительно превосходила аналогичные показатели в контрольной группе и в группе погибших от «быстрого» типа переохлаждения $(\mathrm{p}<0,01)$, достигая в каждом третьем наблюдении 100 и более процентов.

Уровень этанола в других жидких средах (ликвор, желчь, стекловидное тело) колебался в пределах одного наблюдения незначительно, в большинстве случаев не превышая 10-20\%.

Сопоставление коэффициентов отношения этанола в биологических средах к концентрации его в крови показало, что в случаях гибели людей от острой общей гипотермии определяется значительное повышение указанных коэффициентов в сравнении с контрольной группой, что объясняется снижением уровня алкоголемии при использовании организмом этанола из крови как энергетического материала для поддержания теплового гомеостаза.

В фазе равновесия при «быстром типе переохлаждения рост коэффициентов по сравнению с контрольной группой составил для желчи и стекловидного тела $14-15 \%$, ликвора $-6 \%$, мочи - $10 \%$. В фазу элиминации при «медленном» типе переохлаждения увеличение относительных коэффициентов было еще более значительным и составило для желчи и стекловидного тела $-30-31 \%$, ликвора $22 \%$, мочи $-39 \%$.

Степень увеличения коэффициентов зависит от длительности воздействия чрезмерно низкой температуры окружающей среды, так как определяли их достоверно значимый рост в группе погибших от «медленного» типа переохлаждения по сравнению с наблюдениями в группе погибших от «быстрого» типа переохлаждения $(\mathrm{p}<0,05)$. 
К. М. Югов, М. Ю. Зайков. Смерть от акцидентальной гипотермии и экспертная оценка степени алкогольной интоксикации

Для выявления зависимости между снижением энергетических резервов организма и использованием экзогенного алкоголя в биохимических процессах для поддержания теплопродукции при переохлаждении нами проведен регрессионный анализ с определением коэффициента корреляции Пирсона между изменением содержания гликогена в скелетной мышце и динамикой коэффициентов отношения этилового алкоголя в стекловидном теле и желчи, так как последние не имели значительных индивидуальных колебаний, а средние их значения равномерно увеличивались в зависимости от роста продолжительности воздействия холодового фактора.

Анализ зависимостей показал, что между данными величинами имеется умеренная обратная линейная связь. Коэффициент корреляции составил в обоих случаях 0,67 . Коэффициент детерминации, показывающий долю влияния факториального признака на результативный, составил в каждом случае 0,49.

Учитывая, что в большинстве случаев разнообразие всех факторов, изменяющих кинетику и динамику экзогенного алкоголя в организме при переохлаждении, практически не поддается полному установлению, даже после исследования секционного материала с собранными катамнестическими данными, нами разработана и успешно апробирована на практическом судебно-медицинском материале методика объективной оценки степени алкогольной интоксикации у погибших от переохлаждения, включающая в себя следующие позиции:

1. Установление типа общего переохлаждения, приведшего к смерти, в зависимости от продолжительности воздействия холодового фактора на организм согласно разработанной дифференциально-диагностической схеме.

2. Определение стадии алкогольной интоксикации на момент наступления смерти (равновесия или элиминации) по общепринятому судебно-химическому анализу на этанол систем кровь — моча и кровь — ликвор — моча [7].

3. Обязательное токсикологическое исследование на этанол желчи и стекловидного тела, которые являются стабильными системами при переохлаждении организма.

4. Использование для расчета «истинной» алкоголизации организма разработанной математической формулы и рассчитанных нами поправочных коэффициентов.

Таким образом, изменения соотношений концентраций этанола в различных биологических жидкостях трупа отражены в математической модели, которая позволяет определять «истинное» содержание этилового алкоголя в организме на момент наступления смерти от общего переохлаждения организма, обеспечивая объективный подход судебно-медицинских экспертов к оценке степени алкогольной интоксикации.

\section{Литература}

1. Арьев Т. Я. Холодовая травма // Патологическая физиология экстремальных состояний. Москва, 1973. С. 224-237. Текст: непосредственный.

2. Общее переохлаждение организма. Посмертное промерзание трупа / В. И. Витер, В. В. Пудовкин, В. В. Юрасов [и др.]. Москва, 2012. 99 с. Текст: непосредственный.

3. Десятов В. П. Смерть от переохлаждения организма. Томск, 1977. 128 с. Текст: непосредственный.

4. Капустин А. В. Об определении степени алкогольного опьянения // Судебно-медицинский эксперт. 1994. № 4. С. 17-20. Текст: непосредственный.

5. Клинцевич Г. Н. Поражения холодом. Ленинград: Медицина, 1973. 216 с. Текст: непосредственный. 
6. Котельников В. П. Отморожения. Москва: Медицина, 1988. 256 с. Текст: непосредственный.

7. Новиков П. И. Экспертиза алкогольной интоксикации на трупе. Москва: Медицина, 1967. 128 с. Текст: непосредственный.

8. Райский М. И. К учению о распознавании смерти от холода: автореферат диссертации на соискание ученой степени доктора медицинских наук. Томск, 1907. 27 с. Текст: непосредственный.

9. Шадымов А. Б., Иванова И. В. Смерть от переохлаждения и алкоголь // Актуальные вопросы судебной медицины и экспертной практики: сборник научных трудов. Барнаул, 1998. Вып. 3. С. 142-143. Текст: непосредственный.

10. Шигеев В. Б., Шигеев С. В., Колудорова Е. М. Холодовая смерть. Москва, 2004. 184 с. Текст: непосредственный.

11. Югов К. М., Исаев Ю. С., Лукошкина Т. В. Способ оценки степени алкоголизации при смерти от переохлаждения // Современные вопросы судебной медицины: сборник научных трудов. Владивосток, 2001. С. 127-129. Текст: непосредственный.

Статья поступила в редакиию 09.10.2021; одобрена после рецензирования 25.11.2021; принята к публикачии 22.12.2021.

\title{
DEATH BY ACCIDENTAL HYPOTHERMIA AND EXPERT ASSESSMENT OF ALCOHOL INTOXICATION
}

Konstantin M. Yugov

Cand. Sci. (Medicine), Senior Lecturer,

Dorzhi Banzarov Buryat State University

36a Oktyabrskaya St., Ulan-Ude 670000, Russia

buryatia@sudmed.info

\author{
Maksim Yu. Zaykov \\ Senior Lecturer, \\ Dorzhi Banzarov Buryat State University \\ 36a Oktyabrskaya St., Ulan-Ude 670000, Russia \\ maksim_skuchayu@mail.ru
}

Abstract. Mortality rate due to acute accidental hypothermia in the structure of violent death in various regions of Russia ranges from 1.14 to $7.4 \%$. The most frequent deaths occurred in the $41-50$ age group - the most able-bodied part of the population, and men accounted for about $75 \%$ of the dead. The work is aimed at developing and justifying the forensic criteria for assessing the level of alcohol intoxication in the cases of death by hypothermia on the basis studying the concentration of ethanol in various biological matrices, taking into account the peculiarities of its metabolism. We have developed a method of objective assessment of the level of alcohol intoxication in victims of hypothermia, and successfully tested it on practical forensic medical material, it involve the following steps: establishing the type of hypothermia, the stage of alcohol intoxication at the moment of death, and mandatory toxicological examination.

Keywords: accidental hypothermia, alcohol intoxication, mortality, violent mortality, forensic criteria.

For citation

Yugov K. M., Zaykov M. Yu. Death by Accidental Hypothermia and Expert Assessment of Alcohol Intoxication. Bulletin of Buryat State University. Medicine and Pharmacy. 2021; 2: 23-28 (In Russ.).

The article was submitted 29.10.2021; approved after reviewing 25.11.2021; accepted for publication 22.12.2021. 